Ann. Biol. anim. Bioch. Biophys., 1979, 19 (6), 1647-1654.

\title{
Effects of injections and/or subcutaneous implants of melatonin on pituitary and plasma levels of LH, FSH and PRL in ovariectomized Syrian hamsters.
}

par C. TRAKULRUNGSI $\left({ }^{1}\right)$, R. J. REITER $\left({ }^{2}\right)$, W. K. TRAKULRUNGSI ( $\left.{ }^{1}\right), M . K$. VAUGHAN, L. Y. JOHNSON

\author{
Department of Anatomy, The Universify of Texas \\ Health Science Center at San Antonio \\ 7703 Floyd Curl Drive, San Antonio, Texos 78284 U. S. A.
}

Summary. Adult female Syrian hamsters (64-82 g) were ovariectomized and thereafter maintained under light : dark cycles of $14: 10$. After 56 days of treatment the animals were killed and pituitary and plasma levels of luteinizing hormone (LH), follicle stimulating hormone (FSH) and prolactin (PRL) were measured by radioimmunoassay. Ovariectomy caused marked rises in both the content and concentration of LH and FSH within the pitui. tary gland while pituitary PRL levels fell. Plasma levels of LH and FSH also rose while PRL titers remained unchanged. The daily afternoon injection of melatonin ( $25 \mu \mathrm{g}$ subcutaneously) further increased the accumulation of LH and FSH within the pituitary. These responses to daily melatonin injections were prevented if animals additionally received bi-weekly subcutaneous melatonin-beeswax pellets ( $1 \mathrm{mg}$ melatonin in $24 \mathrm{mg}$ wax) which presumably released melatonin continually.

\section{Introduction.}

Removal of the ovaries from hamsters maintained in long daily photoperiods ( $>12.5 \mathrm{hrs}$ light/day) leads to a significant elevation of both blood and pituitary levels of luteinizing hormone ( $\mathrm{LH}$ ) and follicle stimulating hormone (FSH) while prolactin (PRL) values fall markedly (Goldman and Porter, 1970 ; Goldman ef al., 1971 ; Reiter et al., 1974a ; Seegal and Goldman, 1975). Daily afternoon melatonin injections into intact female hamsters have been shown to inhibit reproduction and greatly alter circulating gonadotrophin levels (Tamarkin et al., 1976). Whether melatonin injections could also change the gonadotrophin and PRL responses to ovariectomy in hamsters has not heretofore been determined. This was the purpose of the present study. In

(1) Present address : Department of Anatomy, The Faculty of Science, Mahidol University, Rama VI Road, Bangkok 4, Thailand.

(2) To whom reprint requests and correspondence should be sent. 
the following experiment both daily injections and subcutaneous deposits of melatonin were compared as to their effects on LH, FSH and PRL levels in adult ovariectomized hamsters.

\section{Material and methods.}

Sixty young adult virgin female Syrian hamsters (Mesocricetus auratus, purchased from Lakeview Hamster Colony, Newfield, N. J.), weighing 64 to $82 \mathrm{~g}$, were maintained in groups of 9 to 11 animals per clear plastic cage in an environmentally controlled room illuminated daily from 06.00 to $20.00 \mathrm{hrs}$ (LD $14: 10$ ). The light intensity ranged between 40 and 50 foot-candles at the level of the cages. The ambient temperature was maintained at $24 \pm 3^{\circ} \mathrm{C}$. Wayne Lab-Blox and tap water provided ad libitum.

Hamsters were allowed 1 week to adjust to the laboratory conditions. At the onset of the experiment, they were randomly divided into 6 groups. One group of 10 animals served as intact controls (group 1). Hamsters in the remaining 5 groups were bilaterally ovariectomized under ether anesthesia and were subjected to the following treatments : daily p.m. (16.45 hrs) diluent (lactated Ringer's solution) injections and bi-weekly implants of beeswax pellets (group II), daily a.m. (09.00 hrs) melatonin $(25 \mu \mathrm{g})$ injections and bi-weekly implants of beeswax pellets (group III), daily p.m. melatonin $(25 \mu \mathrm{g})$ injections and bi-weekly implants of beeswax (group IV), daily p.m. diluent injections and bi-weekly implants of melatonin-beeswax pellets (group $V$ ), and daily p.m. melatonin injections and bi-weekly implants of melatonin-beeswax pellets (group VI). The melatonin-beeswax pellets contained $1 \mathrm{mg}$ melatonin in $24 \mathrm{mg}$ beeswax.

The preparation of the melatonin-beeswax and beeswax pellets has been described elsewhere (Reiter ef al., 1974b). Pellets were implanted subcutaneously on the back region of the hamsters once every other week while the animals were under ether anesthesia.

For the injections, fresh melatonin solutions were prepared in ethanolic-lactated Ringer's everyday just prior to use. The indole (final concentration of $250 \mu \mathrm{g}$ per $\mathrm{ml}$ ) or the lactated Ringer's (Abbott Laboratory) vehicle was injected subcutaneously on the dorsum of the neck region in a volume of $0.1 \mathrm{ml}$ per day.

All animals were sacrificed between 09.00 and $11.00 \mathrm{hrs}$ after they were treated for 56 consecutive days. Following decapitation trunk blood samples were collected in heparinized tubes. Blood samples were centrifuged at $3000 \mathrm{rpm}$ at $4{ }^{\circ} \mathrm{C}$ for $20 \mathrm{~min}$ and plasma were stored (at $-20^{\circ} \mathrm{C}$ ) for subsequent hormone assays. Anterior pituitary glands were dissected free, weighed and disrupted by sonication in $0.5 \mathrm{ml}$ $1 \%$ BSA in 0.5 M BSA phosphate buffer, $\mathrm{pH}$ 7.5. Pituitary homogenates were stored frozen until the time of hormone analyses. At the time of kill animals were also checked for completeness of ovariectomy. The gross appearence of their uteri was noted; a portion was taken from the middle third of one of the uterine horns and was fixed in Bouin's fluid for histological evaluation. Just prior to decapitation, the final body weight of each hamster was recorded.

Pituitary and plasma LH, PRL and follicle stimulating hormone (FSH) levels were 
analyzed using the radioimmunoassay methods of Goldman and Porter (1970), Donofrio et al. (1973/74), and Seegal and Goldman (1975), respectively. Reagents for the assays were provided by the Rat Hormone Distribution Program, NIAMDD. LH and FSH values are expressed in terms of NIAMD-Rat LH-I-4 and NIAMD-Rat FSH-I-3, respectively. Due to the lack of parallelism between rat and hamster PRL inhibition curves, hamster PRL values are expressed in terms of a pool of standard hamster anterior pituitaries (SHAP) (Donofrio ef al., 1973/74). All assays were carried out concurrently in duplicate to avoid interassay variations. Statistical analyses of the data were performed on a Monroe Statistical Programmable Printing Calculator using a one-way analysis of variance (ANOVA) ; this was followed by a t-test for differences among several means.

\section{Results.}

The mean final body weight of the ovariectomized hamsters given afternoon melatonin injections (group IV) was significantly greater $(P<0.05)$ than that of the intact controls (group I) (table 1). All ovariectomized hamsters (groups II-VI) also had

TABLE 1

Body weights and absolute $(\mathrm{mg})$ and relative $(\mathrm{mg} / 100 \mathrm{~g}$ body weight) anterior pituitary gland weights in infact and ovariectomized hamsfers

\begin{tabular}{|c|c|c|c|c|c|}
\hline \multirow{2}{*}{ Group and treatment } & \multirow{2}{*}{$N$} & \multicolumn{2}{|c|}{ Body wt. (g) } & \multicolumn{2}{|c|}{ Ant. pituitary wt. } \\
\hline & & Initial & Final & $\mathrm{mg}$ & $\mathrm{mg} / 100 \mathrm{~g} \mathrm{BW}$ \\
\hline 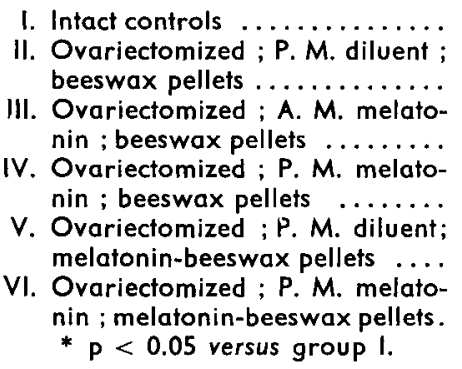 & $\begin{array}{r}10 \\
9 \\
10 \\
10 \\
11 \\
10\end{array}$ & $\begin{array}{l}71 \pm 1 \\
71 \pm 1 \\
73 \pm 2 \\
73 \pm 2 \\
73 \pm 1 \\
74 \pm 2\end{array}$ & $\begin{array}{l}142 \pm 4 \\
141 \pm 7 \\
138 \pm 4 \\
155 \pm 3^{*} \\
144 \pm 4 \\
149 \pm 4\end{array}$ & $\begin{array}{l}4.65 \pm 0.16 \\
5.42 \pm 0.39^{*} \\
5.62 \pm 0.16^{*} \\
5.38 \pm 0.23^{*} \\
5.10 \pm 0.17^{*} \\
5.54 \pm 0.30^{*}\end{array}$ & $\begin{array}{l}3.30 \pm 0.13 \\
3.81 \pm 0.15^{*} \\
4.11 \pm 0.18^{*} \\
3.49 \pm 0.16 \\
3.54 \pm 0.09 \\
3.74 \pm 0.21^{*}\end{array}$ \\
\hline
\end{tabular}

absolutely (mg) larger anterior pituitary glands compared to those in the controls. Although these trends were still apparent when the pituitary weights were expressed relative to body weights $(\mathrm{mg} / 100 \mathrm{~g} \mathrm{BW}$ ) in only three groups were the changes statistically significant.

As anticipated, both the pituitary content and concentration of $\mathrm{LH}$ and $\mathrm{FSH}$ were significantly elevated ( $p<0.001$ versus intact controls) at 56 days following ovariec- 
tomy (fig. 1). Daily afternoon diluent injections in combination with either bi-weekly beeswax (group II) or melatonin-beeswax pellets (group V) had no measurable effect on the levels of either LH or FSH within the pituitary gland. Likewise, a.m. melatonin injections (group III) failed to alter the pituitary LH and FSH responses to ovarieciomy. However, when the melatonin injections were given in the p.m. (group IV) the content and concentration of both LH and FSH were significantly elevated $(p<0.05)$ over those in the other ovariectomized animals. The bi-weekly implantation of melatoninbeeswax pellets (group VI) prevented p.m. melatonin injections from increasing the amount of LH and FSH in the pituitary gland.

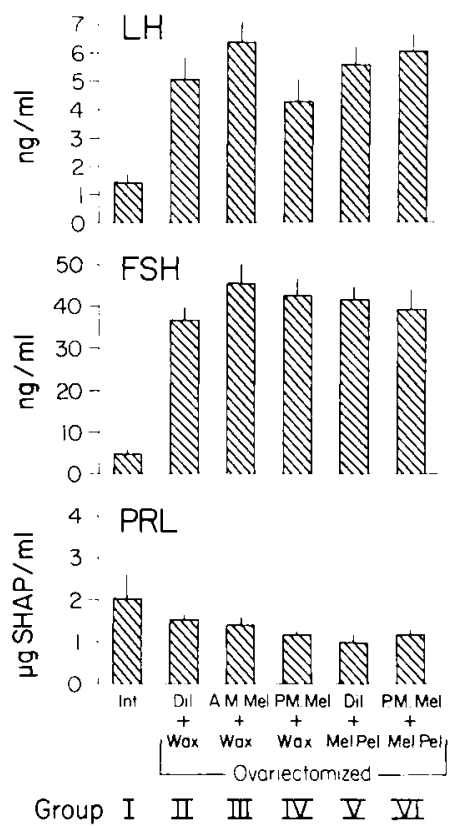

FIG. 1. - Content (clear bars) and concentration (cross-hatched bars) of LH, FSH and PRL in anterior pituitary glands of intact and ovariectomized Syrian hamsters kept under light : dark cycles of $14: 10$. See text for statistical differences between groups. Data as means \pm SE. Dil $=$ daily diluent injections ; Wax = subcutaneous beeswax pellet; $\mathrm{A} . \mathrm{M}$. Mel = daily morning injections of melatonin ; P. M. Mel = daily afternoon injections of melatonin ; Mel Pel = subcutaneous melatonin-beeswax pellet.

Removal of the ovaries was followed by a highly significant $(p<0.001)$ decline in both the content and concentration of pituitary prolactin (fig. 1). None of the other treatments greatly influenced the already markedly reduced pituitary PRL levels.

As illustrated in figure 2, removal of the ovaries was followed by a highly significant $(P<0.001)$ increase in both plasma LH and FSH. Various other treatments employed had no effect on circulating gonadotrophin titers. Neither ovariectomy nor the other procedures statistically significantly influenced radioimmunoassayable PRL levels. 
The uteri of the ovariectomized hamsters were grossly infantile in appearance. Microscopically as well, these uteri appeared atrophic.

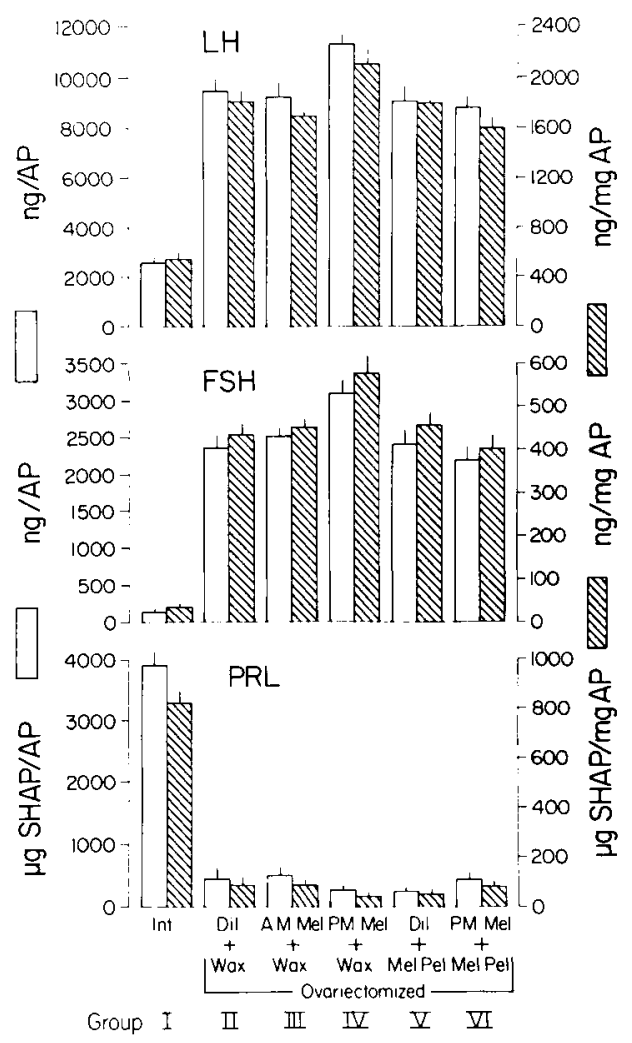

FIG. 2. - Plasma LH, FSH and PRL levels in intact and ovariectomized Syrian hamsters kept under light : dark cycles of $14: 10$. See text for statistical differences between groups. Data as means $\pm \mathrm{SE}$. $\mathrm{Dil}=$ daily diluent injections ; $\mathrm{Wax}=$ subcutaneous beeswax pellet; $\mathrm{A}$. $\mathrm{M}$. Mel $=$ daily morning injections of melatonin ; P. M. Mel = daily afternoon injections of melatonin ; $\mathrm{Mel} \mathrm{Pel}=$ subcutaneous melatonin-beeswax pellet.

\section{Discussion.}

Data on the pituitary and plasma gonadotrophin and prolactin levels after ovariectomy are in agreement with those of earlier reports in which hamsters were utilized as the experimental animal (Goldman and Porter, 1970 ; Goldman ef al., 1971 ; Reiter et al., 1974a ; Seegal and Goldman, 1975). The observed hypertrophic responses of the anterior pituitary glands after removal of the ovaries are also consistent with earlier findings (Reiter et al., 1974a).

In this study the effectiveness of morning (a.m.) versus afternoon (p.m.) injections of melatonin were compared since it has been shown that in intact hamsters only injections given late in the light period are effective in reducing gonadal function (Tamarkin 
ef al., 1976 ; Reiter ef al., 1976). For the same reason (that is, the effectiveness of afternoon injections), it was decided to give the diluent injections in the p.m. also. However, the daily administration of diluent, either alone or in combination with subcutaneous deposits of melatonin, failed to influence the gonadotrophin and PRL responses to ovariectomy. As anticipated from the results of previous studies (Tamarkin et al., 1976), the daily afternoon injection of melatonin significantly altered, in this case increased, pituitary levels of both LH and FSH. These changes could be interpreted as a stimulation of reproductive function by late afternoon melatonin injections. However, it is our opinion that the higher pituitary levels of $\mathrm{LH}$ and FSH really represent an imbalance of these hormones which would have resulted, had the ovaries been intact, in atrophy of the reproductive organs. This statement is made for the following reason. Normally, female hamsters suffering from pineal induced gonadal atrophy have elevated levels of at least LH in their pituitary glands (Reiter and Johnson, 1974). Likewise, circulating LH titers also characteristically increase by virtue of the fact that there is a gonadotrophin surge every afternoon as opposed to every fourth afternoon (Tamarkin et al., 1976). Yet, the ovaries in these animals are anovulatory and the uteri are completely regressed. In long termed ovariectomized hamsters, such as used in the present study, there is no known afternoon surge of LH. This is presumably due to the fact that the pituitary is probably already secreting maximal amounts of $\mathrm{LH}$ since there is no feedback inhibition from ovarian steroids.

Considerably less is known about the regulation of FSH by melatonin. Tamarkin and colleagues (1976) reported that, like LH, FSH titers rise every afternoon in female hamsters with melatonin-induced gonadal regression. Since in the present study the hamsters had been castrated for 56 days there was likely no afternoon surge of FSH. To the present authors' knowledge no one has heretofore reported on the levels of FSH in the pituitary glands of hamsters in which the reproductive systems were atrophic due to the daily administration of melatonin.

One of the most remarkable findings in the present study was the significant elevation of pituitary LH and FSH in ovariectomized females injected with melatonin every afternoon. Ovariectomy is generally considered to be a very powerful stimulus for the accumulation of LH and FSH within the pituitary ; yet, p.m. melatonin injections were capable of further augmenting the gonadotrophin stores within the hypophyses. This suggests that the pineal constituent melatonin may play an important role in determining the quantity of $\mathrm{LH}$ and $\mathrm{FSH}$ normally stored within the pituitary gland of female hamsters.

The fact that subcutaneous melatonin pellets prevented the effects of daily afternoon melatonin injections on pituitary $\mathrm{LH}$ and $\mathrm{FSH}$ levels was not completely unexpected. We have previously found that the gonadal involution induced in intact male hamsters by daily afternoon melatonin injections is also prevented by placing reservoirs of melatonin subcutaneously (Reiter ef al., 1977). It has now been shown that similar relationships exist in ovariectomized female hamsters, i.e., that subcutaneous reservoirs of melatonin prevent the action of daily melatonin injections. Several potential explanations for the apparently paradoxical finding have been proposed (Reiter et al., 1977). The most likely of these explanations relates to the responsivity of the melatonin receptors. We are currently working under the assumption that continually available melatonin (e.g., from a subcutaneous deposit) normally down regulates 
(desensitizes) its receptors so that melatonin injected daily will not act. This hypothesis would explain the inability of afternoon injections to alter pituitary $\mathrm{LH}$ and $\mathrm{FSH}$ values when the animals also possess a subcutaneous reservoir of the indoleamine.

\section{Conclusions.}

Ovariectomy in adult female hamsters causes marked rises in both the content and concentration of LH and FSH within the pituitary gland while pituitary PRL levels fall sharply. Under the same circumstances, plasma levels of LH and FSH are also increased while prolactin titers remain unchanged. The daily afternoon injection of melatonin into castrated females further increases the accumulation of $\mathrm{LH}$ and FSH within the pituitary glands. The responses to acute daily melatonin injections are prevented if animals additionally receive bi-weekly subcutaneous melatonin-beeswax pellets which presumably release melatonin continually. Thus, chronically available melatonin (from subcutaneous reservoirs) prevents the action of acute daily injections of the indoleamine.

Reçu en janvier 1979.

Accepté en avril 1979.

Acknowledgements. - Supported by NSF Grant No. PCM-77-05734 and NIH Center Grant for Research in Reproductive Biology No. 30-HD-10202. C. T. was a Postdoctoral Fellow of the Rockefeller Foundation.

Résumé. Des hamsters dorés (Mesocricetus auratus) adultes $(64-82 \mathrm{~g})$, de sexe féminin, ont été ovariectomisés puis maintenus dans les conditions de $24 \mathrm{~h}$ de lumière et $10 \mathrm{~h}$ d'obscurité, par jour. Après 56 jours, les animaux furent sacrifiés ef les taux antéhypophysaire et plasmatique d'hormones lutéinisante (LH), folliculo-stimulante (FSH) et de prolactine (PRL) onł été obtenus par dosage radioimmunologique. L'ovariectomie provoque, dans l'antéhypophyse, une nette augmentation à la fois du contenu et de la concentration de LH et FSH ef une chute de PRL. Dans le plasma, LH et FSH augmentent également alors que la PRL est inchangée. L'injection sous-cutanée quotidienne de mélatonine $(25 \mu \mathrm{g})$, au cours de l'après-midi, accroît davantage l'accumulation de la LH et de la FSH antéhypophysaires. Ces réponses aux injections quotidiennes de mélatonine sont supprimées lorsque les animaux reçoivent en plus, deux fois par semaine, des implants sous-cutanés (1 $\mathrm{mg}$ de mélatonine dans $24 \mathrm{mg}$ de cire d'abeille) qui libèrent probablement la mélatonine de façon continue.

\section{References}

DONOFRIO R. J., REITER R. J., SORRENTINO S. Jr., BLASK D. E., TALBOT J. A., 1973/74. A method of measurement of prolactin in the hamster by means of radioimmunoassay. Neuroendocrinology, 13, 79-91.

GOLDMAN B. D., PORTER J. C., 1970. Serum LH levels in intact and castrated golden hamsters. Endocrinology, 87, 676-679.

GOLDMAN B. D., MAHESH V. B., PORTER J. C., 1971. The role of the ovary in control of cyclic LH release in the hamster Mesocricetus auratus. Biol. Reprod., 4, 57-65.

REITER R. J., JOHNSON L. Y., 1974. Elevated pituitary LH and depressed pituitary prolactin levels in female hamsters with pineal-induced gonadal atrophy and the effects of chronic treatment with synthetic LRF. Neuroendocrinology, 14, 310-320. 
REITER R. J., BLASK D. E., JOHNSON L. Y., 1974a. Influence of ovariectomy and estrogen and/or progesterone treatment on pituitary and plasma LH and prolactin levels in female hamsters. Endocr. Res. Commun., 1, 181-191.

REITER R. J., VAUGHAN M. K., BLASK D. E., JOHNSON L. Y., 1974b, Melatonin : its inhibition of pineal antigonadotrophic activity in male hamsters. Science, 185, 1169-1170.

REITER R. J., BLASK D. E., JOHNSON L. Y., RUDEEN P. K., VAUGHAN M. K., WARING P. J., 1976. Melatonin inhibition of reproduction in the male hamster : Its dependency on time of day of administration and on an intact and sympathetically innervated pineal gland. Neuroendocrinology, 22, 107-116.

REITER R. J., RUDEEN P. K., SACKMAN J. W., VAUGHAN M. K., JOHNSON L. Y., LITTLE J. C., 1977. Subcutaneous melatonin implants inhibit reproductive atrophy in male hamsters induced by daily melatonin injections. Endocr. Res. Commun., 4, 35-44.

SEEGAL R. F., GOLDMAN B. D., 1975. Effects of photoperiod on cyclicity and serum gonadotropins in the Syrian hamster. Biol. Reprod., 12, 223-231.

TAMARKIN L., WESTROM W. K., HAMILL A. I., GOLDMAN B. D., 1976. Effect of melatonin on the reproductive systems of male and female Syrian hamsters : A diurnal rhythm in sensitivity to melatonin. Endocrinology, 99, 1534-1541. 